\title{
ALAT MONITORING SUHU MELALUI APLIKASI ANDROID MENGGUNAKAN SENSOR LM35 DAN MODUL SIM800L BERBASIS MIKROKONTROLER ATMEGA16
}

\author{
I Kadek Agus Sara Sawita ${ }^{1}$, I Wayan Supardi' ${ }^{1}$ I Gusti Agung Putra Adnyana1
}

\author{
${ }^{1}$ Jurusan Fisika FMIPA, Universitas Udayana, Badung, Indonesia \\ *Email: agussarasawita@gmail.com
}

\begin{abstract}
Abstrak
Telah berhasil dibuat alat monitoring suhu melalui aplikasi android menggunakan sensor LM35 dan modul SIM800L berbasis mikrokontroler ATmegal6. Suhu diukur menggunakan sensor LM35 dan sebagai pemroses utama digunakan mikrokontroler ATMega16. Suhu terukur dikirim dan disimpan di database pada komputer server menggunakan modul SIM800L sehingga bisa ditampilkan pada website. Halaman website diakses dengan program android yang telah di-instal pada smartphone sehingga data suhu terukur dapat dimonitor menggunakan smartphone. Hasil pengukuran suhu alat monitoring memiliki rata-rata standar deviasi sebesar $\pm 0,31$. Ini menunjukkan hasil pengukuran alat monitoring cukup akurat.
\end{abstract}

Kata kunci: sensor LM35, SIM800L, mikrokontroler ATMega16, android.

\begin{abstract}
It has been successfully designed a temperature monitoring instrument through android application using LM35 sensor and SIM800L module based on ATMegal6 microcontroller. The temperature is measured using a LM35 sensor and microcontroller ATMegal6 is using as the main processor. The measurable temperature is sent and saved in the database on the server computer using the SIM800L module so it can be displayed on the website. The website pages are accessed with android programs that installed on the smartphone so that measurable temperature data can be monitored using a smartphone. The results measurement of monitoring instrument have an average standard deviation \pm 0.31. This indicate the measurement results of the monitoring instrument is quite accurate.
\end{abstract}

Keywords: LM35 sensor, SIM800L, ATMegal6 microcontroller, android.

\section{Pendahuluan}

Pemakaian smartphone berbasis android semakin meningkat dikalangan masyarakat dengan fitur-fitur yang ditawarkan semakin banyak. Sifat android yang open source membuat banyak developer tertarik mengembangkannya. Operation System (OS) android mudah digunakan sehingga dapat di kembangkan di banyak platform hardware [1] Salah satu pemanfaatan teknologi android ini digunakan untuk memonitoring suhu.

Sistem monitoring konvensional terdapat kelemahan, yaitu ketidakakuratan data dan ketidakpraktisan dalam monitoring. Monitoring suhu akan lebih praktis jika dilakukan dengan aplikasi android, sehingga dalam monitoring dapat dilakukan dari jarak jauh. Pencatatan suhu yang dilakukan berkala dan terus menerus secara manual masih kurang akurat, sehingga membuat pekerjaan tersebut tidak efisien. Misalnya, pencatatan suhu dari sebuah pabrik, gunung, kota, ruang pembakaran dan lain-lain. Pencatatan suhu akan lebih efisien jika menggunakan komputer sebagai media pencatatan dan penyimpanan data suhu yang terukur.

Berdasarkan pemaparan di atas, maka peneliti berinisiatif untuk membuat alat monitoring suhu yang dapat dipantau melaui aplikasi android dan hasil suhu yang terukur dapat disimpan melalui database pada komputer. Pembuatan alat monitoring suhu ini menggunakan sensor LM35 dan modul SIM800L berbasis mikrokontroler ATMega16. Dengan adanya alat monitoring suhu ini diharapkan dapat membantu kehidupan manusia seperti pencatatan suhu sebuah pabrik, gunung, kota atau bahkan ruang pembakaran dengan 
mudah dan tanpa harus datang ke lokasi tersebut.

\section{Tinjauan Pustaka \\ 2.1. Sensor Suhu LM35}

Fungsi sensor suhu LM35 adalah mengubah suhu yang merupakan besaran fisis menjadi besaran elektrik berupa tegangan. Parameter sensor ini memilki batas maksimal keluaran 1,5 $\mathrm{V}$ pada suhu $150{ }^{\circ} \mathrm{C}$ dengan kenaikan keluaran sebesar $10 \mathrm{mV}$ setiap kenaikan $1{ }^{\circ} \mathrm{C}$ [2]. Diagram sensor suhu LM35 ditunjukkan pada Gambar 1 [3].

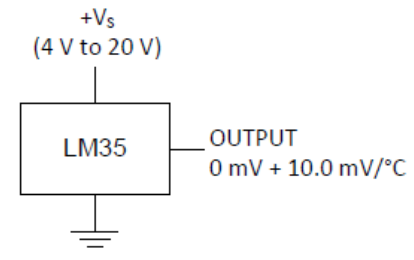

Gambar 1. Diagram sensor suhu LM35.

\subsection{Modul SIM800L}

SIM800L merupakan suatu modul Global Standard for Mobile Communications (GSM) yang dapat mengakses General Packet Radio Service (GPRS). Modul SIM800L cocok diaplikasikan pada alat rancangan yang didesain portable karena memilki bentuk yang kecil [4]. Berikut merupakan modul SIM800L yang diperlihatkan pada Gambar 2 [5].

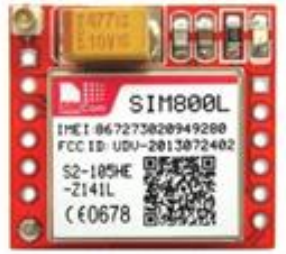

Gambar 2. Modul SIM800L.

\subsection{Mikrokontroler ATMega16}

Mikrokontroler Alf and Vegard's Rise Processor (AVR) memiliki arsitektur Reduced Instruction Set Computing (RISC) 8 bit, di mana sebagian besar intruksi dieksekusi dalam satu siklus clock dan semua intruksi dikemas dalam kode 16 bit. Salah satu chip mikrokontroler jenis AVR yang banyak digunakan adalah tipe ATMega16 yang mempunyai optimasi konsumsi daya terhadap kecepatan proses karena memiliki throughput mendekati 1 MIPS per MHz. Kelebihan dari ATMega16 adalah sudah ada Analog to Digital Converter (ADC) di dalamnya. ADC merupakan sebuah piranti pengkonversi sinyal analog kedalam sinyal digital. Mode operasi
ADC ATMega16 dapat dikonfigurasi sesuaikan dengan kebutuhan dari ADC itu sendiri [6]. Mikrokontroler ATMega16 mempunyai 40 pin, konfigurasi pin tersebut ditunjukkan pada Gambar 3 [7].

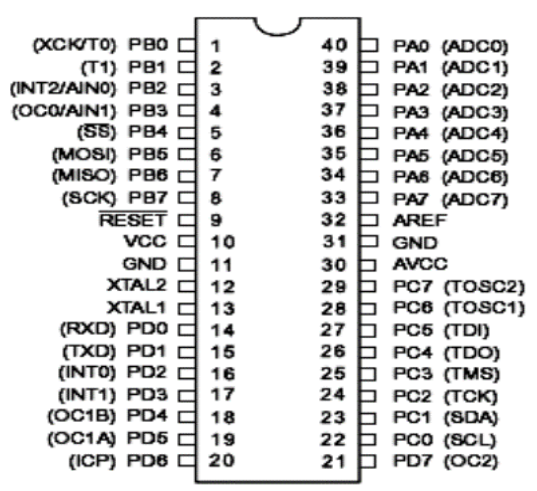

Gambar 3. Konfigurasi pin mikrokontroler ATmega16.

\subsection{Perintah AT (AT Command)}

AT Command ialah perintah atau instruksi yang dikenakan pada modem atau handset. Penggunaan AT Command berfungsi untuk mengetahui vendor handphone yang digunakan, mendeteksi pesan masuk, mengirim serta menghapus pesan SMS, membuka koneksi General Packet Radio Service (GPRS) dan lainlain [8].

\subsection{MySQL}

MySQL banyak digunakan untuk mengelola database karena bersifat open source. Sifat tersebut membuat perangkat lunak ini dapat digunakan secara bebas tanpa harus membayar, selain hal tersebut source code dari MySQL dapat di unduh secara bebas oleh siapapun [9].

\subsection{Android}

Seiring perkembangan android yang sangat pesat, android berkembang dan berubah dari sebuah sistem operasi menjadi platform. Platform android terdiri dari, Graphical User Interface (GUI), web browser, aplikasi end-user serta sistem operasi berbasis Linux, yang dapat di unduh dan juga dikembangkan dengan leluasa, sehingga dapat diciptakan aplikasi yang bisa digunakan untuk berbagai platform hardware [10].

\section{Metode Penelitian}

\subsection{Diagram Blok Alat}

Diagram blok perancangan alat monitoring 
suhu melalui aplikasi android menggunakan sensor LM35 dan modul SIM800L berbasis mikrokontroler ATMega16 ditunjukkan pada Gambar 4.

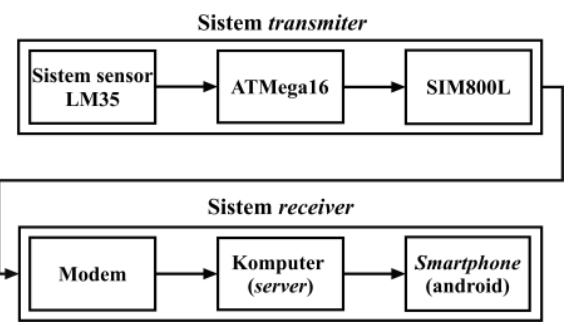

Gambar 4. Diagram sensor suhu LM35.

\subsection{Diagram Alir Program}

Adapun diagram alir atau flow chart program mikrokontroler ATMega16 pada rangkaian penguji sebagai pendukung kalibrasi sensor suhu LM35 serta rangkaian modul SIM800L sebagai alat pengirim sinyal hasil ukur suhu ke komputer server sehingga bisa diproses dan ditampilkan pada aplikasi android. Diagram alir (flow chart) program ditunjukkan pada Gambar 5 .

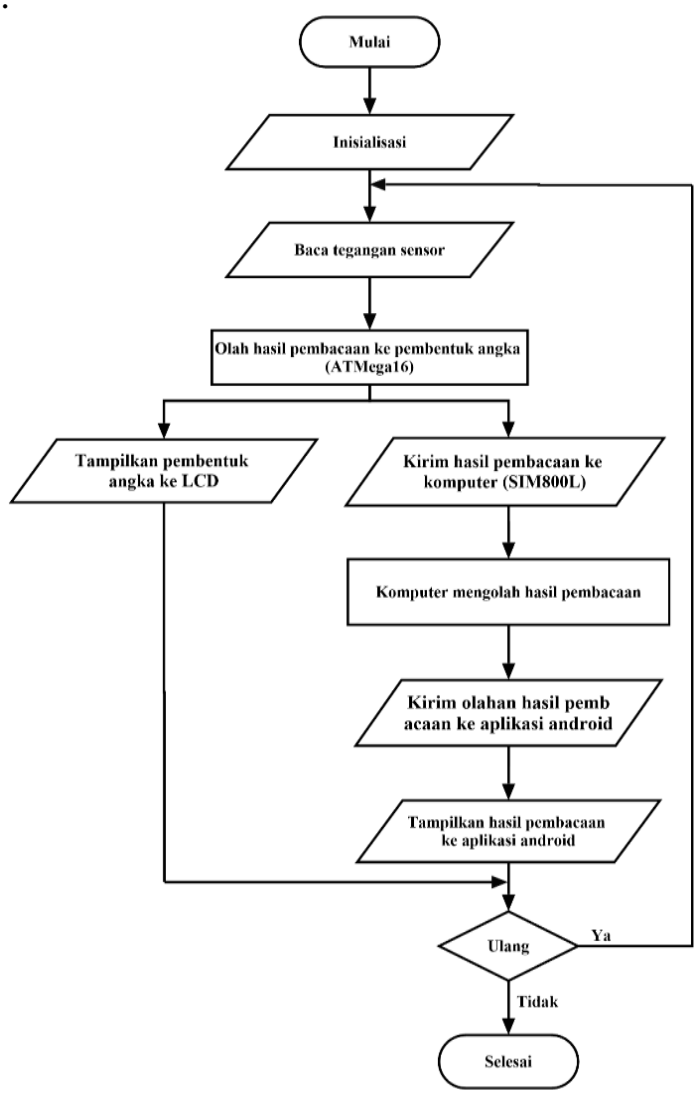

Gambar 5. Diagram alir (flow chart) program.

\section{Hasil Dan Pembahasan}

\subsection{Hasil}

Telah diperoleh hasil dari penelitian ini adalah alat monitoring suhu melalui aplikasi android menggunakan sensor LM35 dan modul SIM800L berbasis mikrokontroler ATMega16. Alat monitoring ini terdiri dari beberapa bagian utama serta tampilan monitoring suhu pada smartphone ditunjukkan pada Gambar 6.

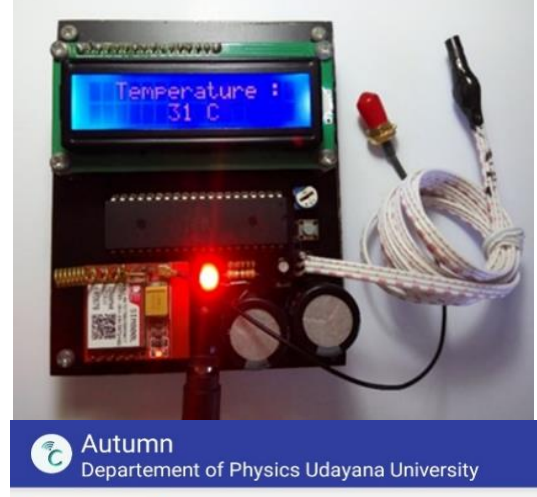

\section{$<$ Back}

\begin{tabular}{|l|l|l|}
\hline \multicolumn{3}{|l|}{ Automatic Temperature Monitoring } \\
\hline No & Temperature (C) & Date and Time \\
\hline 1 & 31 & $2017-06-05$ 10:46:47 \\
\hline 2 & 31 & $2017-06-0510: 46: 37$ \\
\hline 3 & 31 & $2017-06-0510: 46: 29$ \\
\hline 4 & 31 & $2017-06-0510: 46: 24$ \\
\hline 5 & 31 & $2017-06-0510: 46: 15$ \\
\hline
\end{tabular}

Gambar 6. Alat monitoring suhu menggunakan sensor LM35 dan modul SIM800L berbasis mikrokontroler ATMega16 dan tampilan pada smartphone.

\subsection{Pembahasan Hardware Dan Software}

Sensor LM35 memilki respon yang mengubah suhu yang terditeksi menjadi tegangan. Tegangan yang dihasilkan memilki perubahan yang sebanding dengan suhu yang dideteksinya. Tegangan yang dihasilkan dari sensor LM35 dihubungkan ke mikrokontroler ATMega16 pada pin PA0 yang merupakan masukkan Analog to Digital Converter (ADC).

ADC pada mikrokontroler ATMega16 mengkonversikan sinyal analog dari sensor LM35 yang berupa tegangan menjadi data digital. Pengkonversian dan pengolahan data yang diterima mikrokontroler diatur oleh program yang di-download pada mikrokontroler ATMega16. Setelah data diolah, data ditampilkan pada alat penampil berupa Liquid Crystal Display (LCD). Data yang ditampilkan berupa nilai suhu yang terukur oleh sensor LM35 dalam satuan celcius. Data digital yang diperoleh dikirimkan ke komputer server melalui modul SIM800L yang diintruksikan oleh program pada mikrokontroler ATMega16. 
Modul SIM800L dihubungkan ke mikrokontroler ATMega16 sehingga terjadi komunikasi serial antar keduanya. Pin TXD SIM800L dihubungkan ke pin PD0 (RXD) mikrokontroler ATMega16, begitupun pin RXD SIM800L dihubungkan ke pin PD1 (TXD) ATMega16.

Data digital berupa suhu terukur dikirim oleh Modul SIM800L melalui General Packet Radio Service (GPRS) ke komputer server. Komputer yang sudah terkoneksi internet menerima dan menyimpan data digital tersebut satu persatu ke dalam database. Selanjutnya data suhu yang diterima server ditampilkan pada website. Program android yang sudah di-instal pada smartphone mengakses halaman website tersebut sehingga data suhu yang terukur dapat dilihat di smartphone.

\subsection{Desain Database}

Desain database ditunjukkan pada Gambar 7, database berfungsi sebagai tempat penyimpan data suhu terukur pada komputer server. Terdapat 3 buah field pada database ini yaitu id_suhu, suhu dan jam. Tipe data id_suhu dan suhu yaitu int (integer) sedangkan untuk tipe jam yaitu datetime. Data dari id_suhu memiliki 11 panjang data dan suhu memiliki 3 panjang data. Data id_suhu memliki extra AUTO_INCREMENT dan data jam memiliki pengaturan default yaitu CURRENT_TIMESTAMP.

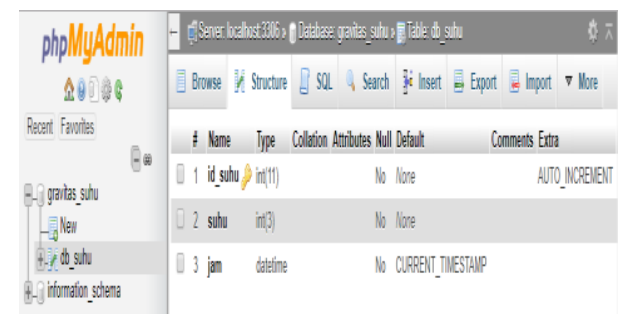

Gambar 7. Desain database.

\subsection{Kalibrasi}

Kalibrasi alat monitoring suhu melalui aplikasi android menggunakan sensor LM35 dan modul SIM800L berbasis mikrokontroler ATMega16 dilakukan dengan cara membandingkan hasil pengukuran suhu dari 0 ${ }^{\circ} \mathrm{C}$ sampai $99{ }^{\circ} \mathrm{C}$ dengan termometer digital standar merk TM-902C. Data kalibrasi tegangan keluaran hasil rancangan alat ukur sebagai fungsi suhu seperti ditunjukkan pada Gambar 8.

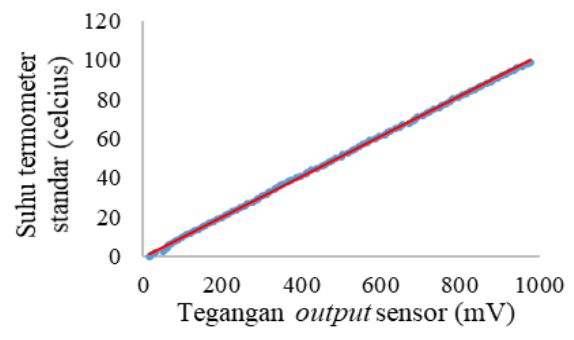

Gambar 8. Grafik suhu termometer standar terhadap tegangan output sensor.

Gambar 8 menunjukkan bahwa perubahan respon tegangan keluaran sensor LM35 mengalami peningkatan seiring dengan bertambahnya suhu yang terukur. Berdasarkan data karakteristik sensor LM35 yang ditunjukkan pada Gambar 8 dilakukan penyusaian pada program yang di-download ke mikrokontroler ATMega16.

\subsection{Pengujian Alat Rancangan}

Pengujian rancangan alat monitoring suhu melalui aplikasi android menggunakan sensor LM35 dan modul SIM800L berbasis mikrokontroler ATMega16 dilakukan dengan cara membandingkan hasil pengukuran alat rancangan dengan termometer digital standar merk TM-902C dengan mengambil data pengukuran suhu pada rentang $0{ }^{\circ} \mathrm{C}$ sampai 99 ${ }^{\circ} \mathrm{C}$. Data pengujian alat yang telah diperoleh kemudian ditampilkan dalam bentuk sebuah grafik seperti yang ditunjukkan pada Gambar 9 .

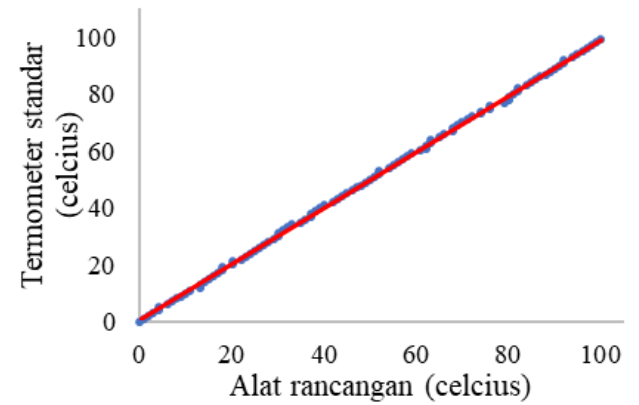

Gambar 9. Grafik suhu termometer standar terhadap alat rancangan.

Gambar 9 menunjukkan grafik kelinieran hasil pengukuran suhu pada rentang $0{ }^{\circ} \mathrm{C}$ sampai $99{ }^{\circ} \mathrm{C}$ oleh alat rancangan dengan termometer standar. Hasil analisa data pengujian alat rancangan dapat diperoleh nilai koefisien determinasi yaitu sebesar 0,9997. Nilai koefisien yang didapat menyatakan bahwa kesesuaian alat rancangan dengan termometer standar adalah sebesar 99,97 \% sedangkan sisanya terjadi ketidaksesuaian. Masih terjadi ketidak sesuaian pada hasil pengukuran 
kemungkinan diakibatkan oleh sensitivitas sensor dari alat rancangan yang berbeda dari termometer standar.

Agar hasil pengukuran suhu alat rancangan sama dengan termometer standar maka digunakan rumus Persamaan 1. Persamaan 1 merupakan persamaan regresi linier suhu termometer standar dengan alat rancangan pada Gambar 9.

$$
y=0,9865 x+0,5098
$$

Dimana: $y=$ nilai suhu termometer yang sesungguhnya $\left({ }^{\circ} \mathrm{C}\right)$

$x=$ nilai suhu alat rancangan $\left({ }^{\circ} \mathrm{C}\right)$

Hasil beberapa mengukuran suhu dari termometer standar dan alat rancangan serta selisih dari kedua hasil pengukuran tersebut ditunjukkan pada Tabel 1. Dari Tabel 1 dapat dilihat bahwa perbedaan hasil kedua pengukuran sangat kecil, secara rata-rata deviasinya $\pm 0,31$. Ini menunjukkan hasil pengukuran dari alat yang dibuat cukup akurat.

Tabel 1. Pengukuran suhu

\begin{tabular}{cccc}
\hline & \multicolumn{2}{c}{ Suhu $\left({ }^{\circ} \mathrm{C}\right)$} & \\
\cline { 2 - 3 } No & Standar & $\begin{array}{c}\text { Alat } \\
\text { rancangan }\end{array}$ & Selisih \\
\hline 1 & 0 & 0 & 0 \\
2 & 1 & 1 & 0 \\
3 & 2 & 2 & 0 \\
4 & 3 & 3 & 0 \\
5 & 4 & 4 & 0 \\
6 & 5 & 4 & 1 \\
7 & 6 & 6 & 0 \\
8 & 7 & 7 & 0 \\
9 & 8 & 8 & 0 \\
10 & 9 & 9 & 0 \\
\hline
\end{tabular}

\section{Kesimpulan}

\subsection{Kesimpulan}

Kesimpulan yang diperoleh berdasarkan penelitian yang dilakukan yaitu telah berhasil dibuat alat monitoring suhu melalui aplikasi android menggunakan sensor LM35 dan modul SIM800L berbasis mikrokontroler ATMega16. Hasil suhu terukur dapat dipantau melaui aplikasi android dan dapat disimpan melalui database pada komputer. Hasil pengukuran suhu alat monitoring memiliki rata-rata standar deviasi sebesar \pm 0.31 . Ini Menunjukkan hasil pengukuran alat monitoring cukup akurat.

\section{Daftar Pustaka}

[1] Nuryuliani, dkk., Aplikasi Pencarian Lokasi
Sekolah Menggunakan Telepon Selular Berbasis Android, Prosiding Seminar Ilmiah Nasional Komputer dan Sisstem Intelijen (2012), hlm 331

[2] Imam Santoso, Sistem Monitoring Suhu Berbasis Web dengan Akuisisi Data Melalui Port Paralel PC, Jurusan Teknik Elektro Fakultas Teknik Universitas Diponegoro, (2008)

[3] Anonim, LM35 Precision Centigrade Temperature Sensors, https:// recherchetechnologie.wallonie. servlet/Repository/oct2015_lm35.pdf. Diakses pada tanggal 28 Maret 2016

[4] Anggara Wijaya, Implementasi Telemetri Pengamatan Profil Cuaca dan Kualitas Udara di Gunung Tangkuban Perahu, Program Studi Teknik Telekomunikasi Fakultas Ilmu Terapan Universitas Telkom (2015)

[5] Rifki Reinaldo dan Yudo Prakoso, Pendeteksian Suhu Sekitar Menggunakan Sensor Suhu LM35 Berbasis Mikrokontoler AVR ATMega16, Jurusan Fisika Fakultas Matematika dan Ilmu Pengetahuan Alam Universitas Negeri Jakarta (2015)

[6] Anonim, LoNet-GSM/GPRS Breakout. http://www.seeedstudio.com/wiki/LoNetGSM/GPRS Breakout. Diakses pada tanggal 10 April 2016

[7] Heri Andrianto, Pemrograman Mikrokontroler AVR ATMega16 Menggunakan Bahasa C (Code Vision AVR), Informatika Bandung (2015)

[8] Denis, Pengendalian Motor Induksi 3 Fasa Berbasis SMS Controller Menggunakan Bahasa Pemrograman BASCOM Memanfaatkan Modem Wavecom Fastrack yang di Interface dengan Mikrokontroller AT 16, Jurusan Teknik Elektro Fakultas Teknik Universitas Diponegoro (2013)

[9] Suherman, Rancang Bangun Alat Ukur Temperatur Suhu Perangkat Server Menggunakan Sensor LM35 Bebasis SMS Gateway, Jurusan Sistem Komputer Fakultas Teknologi Informasi Universitas Serang Raya (2015)

[10] Akhmad Dharma Kasman, Kolaborasi Dahsyat Android dengan PHP dan MySQL. Lokomedia Yogyakarta (2013). 